http://www.jfas.info

\title{
NEW DESIGN ALGORITHM AND RELIABILITY TESTING OF SOLAR POWERED NEAR-SPACE FLIGHT VEHICLE FOR DEFENSE AND SECURITY
}

\author{
A. C. Idris ${ }^{*}$, N. Dollah, M. R. Saad, S Sojipto and M. R. A. Rahman \\ Faculty of Engineering, National Defence University of Malaysia, Sg. Besi Camp, 57000 \\ Kuala Lumpur, Malaysia
}

Published online: 10 September 2017

\begin{abstract}
Broadband telecommunications have become the key factor for economic growths around the world, but rural and hard to reach areas are missing out on the opportunity. To overcome this problem, we propose a pseudo-satellite system where telecommunication devices are carried on a perpetually flying solar aircraft cruising at stratospheric altitude. Our aircraft will combine lighter-than-air technology to augment the lift from the wing. Every major components contributing to the aircraft total weight has been considered, resulting in a range of design solutions. We chose wing span and aspect ratio of $50 \mathrm{~m}$ and 13 respectively, from which other specifications of the aircraft were fixed to. Our design solution has been validated by power and weight balance analysis. System reliability has been demonstrated by Monte Carlo simulation.
\end{abstract}

Keywords: inflatable aircraft; lighter-than-air; solar aircraft; high amplitude platform (HAP).

Author Correspondence, e-mail: azam.che@gmail.com

doi: http://dx.doi.org/10.4314/jfas.v9i3s.35 


\section{INTRODUCTION}

Near space region has been the focus of many military research institutions due to its huge potential and strategic importance. The term near-space is defined as the air space between 12 to 62 miles (about 19 to $100 \mathrm{~km}$ ) of altitude, where above $100 \mathrm{~km}$ is widely considered as a sub-orbital outer space region. The characteristic of near-space region is that its atmosphere is too rarefied to the extent that conventional winged flight is very difficult (but not impossible), while at the same time gravity is too strong for a satellite to orbit. If for example a pseudo-satellite could be placed on station between these heights, reduction of total life-cycle cost and increase in responsiveness can be achieved [1]. Aircrafts that can carry a satellite-capable system in the near space region are called high altitude platforms (HAP) [2].

The image capturing capabilities of an HAP carrying intelligence-surveillance-reconnaissance (ISR) equipment's is much superior to those of a satellite due to its closer distance to earth surface. This is the reason why United States Air Force (USAF) employed Lockheed's U2 high altitude long endurance (HALE) spy-plane, which flew at 70,000 feet $(21 \mathrm{~km})$ altitude for reconnaissance purpose [3]. This aircraft is still in service surviving the budget cut which ended the life of another high altitude ISR, the SR71 Blackbird. However, the USAF are also actively looking to design a successor to U2 as the current system requires two pilots to fly for 8 hours before landing for refuel. In comparison, a perpetual HAP system without the need to land and refuel would be much better as a pseudo-satellite system.

HAP can be inserted into its intended altitude ad-hoc during battle to connect all disparate elements and assets being deployed by the field commander. The HAP could simply act as node to relay between a broadcast to receivers or it could become the hub to connect all incoming and outgoing data streams such as depicted in Fig. 1 [4]. Current communication standards such as BOWMAN, JTIDS/Link16 can be adopted easily by an HAP system. As a replacement for military communication satellite (MILCOMSAT), a pseudo-satellite aboard of an HAP can operate at EHF (45/20) GHz which are still uncluttered and has large spectral availability. The EHF also has Low Probability of Intercept (LPI) [5]. Range of communications is between 120 to 270 miles depending on the elevation angle of the broadcast and receiver beam [4]. The platform itself is stealthy with low radar signature which 
shielded it from enemy detection during active battle. Although possible, there are only a handful of surface to air missiles that can reach the near space altitude [5].

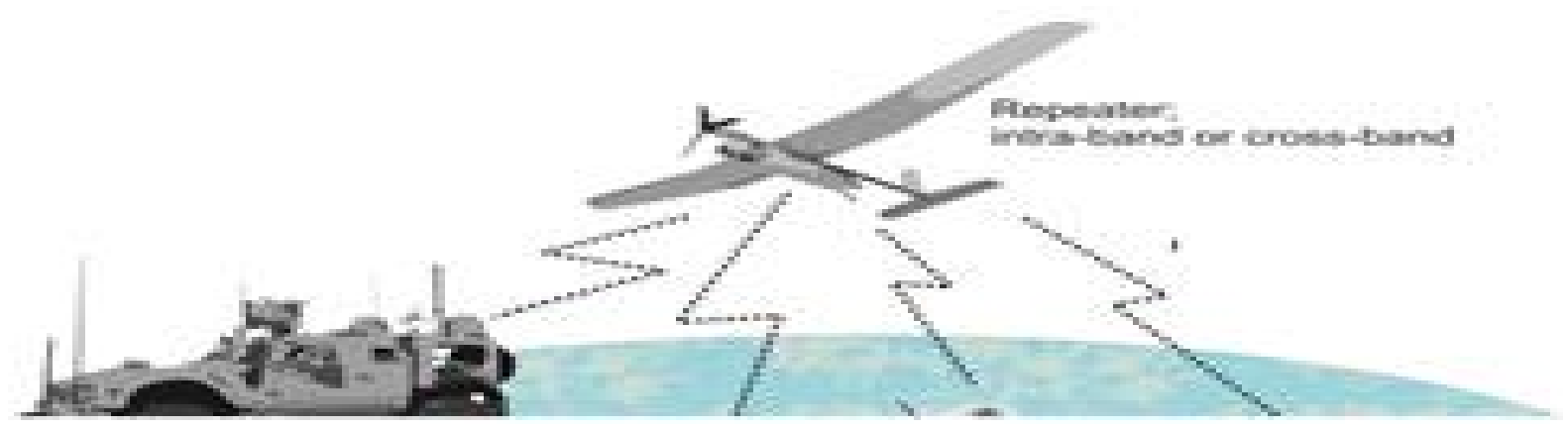

Fig.1. Personal communication system for beyond line of sight battlefield communications without the need for terrestrial infrastructure

Beside communication, HAP could also carry a portable radar system for over the horizon surveillance. Missile Defence Agency (MDA) in the USA proposed a high altitude radar system, weighing not more than $500 \mathrm{lbs}$, carried by an airship for cruise missile detection [6]. The potential is huge since at $20 \mathrm{~km}$ altitude the radar coverage is about $500 \mathrm{~km}$ radius and radar would not be affected by any cloud layer in the troposphere (below $18 \mathrm{~km}$ altitude) [7]. HAP fitted with a good resolution camera can be used effectively as a remote sensing system to observe disaster prone region. In Flemish Institute of Technological Research (VITO), they are experimenting with a system that can capture image with sensitivity of $30 \mathrm{~cm}$ from $18 \mathrm{~km}$ altitude using a camera weighing no more than $3 \mathrm{~kg}$ [8]. FiRE project in the USA and COMETS in Europe are developing forest surveillance equipment using high-altitude Unmanned Aerial Vehicle (UAV) to monitor wild forest fire [9]. This kind of system have better resolution in detecting forest fire since the platform is closer to surface in comparison to a satellite thus giving a very early warning before the fire could spread further. There are also studies that concentrate on the role an HAP could play in post-disaster situation. Ad-hoc communication network using the HAP is easy to set-up and can allows for quick connection among disperse rescue workers and victims. The added benefit of using the HAP for post-disaster communication network is that victims' cell phone location can be triangulated easily by determining time of arrival (DOA) and time delay of arrival (TDOA) as long as the exact position of a moving HAP is known all the time [10]. 
A perpetual flying HAP for defense, security and disaster management must have a rapid deployment mechanism to reach its intended altitude quickly in an emergency [2]. A large airship with speed of only 30 knots could take days to reach their operating altitude. A large airship is also vulnerable to weather unpredictability. It is clear that airship technology is not enough and must include modifications to improve its deployment speed. Thus, in this paper, we devise an optimization procedure for the design of an HAP flying using conventional wing lift (for fast deployment) that is augmented by lighter-than-air technology (for higher payload capacity).

Since we endeavor to incorporate conventional lift from wing for our design, we are at the mercy of the sun to supply power for high cruise speed. Solar powered airplane technology has gone a long way since the first one invented in 1974 by R.J. Boucher [11]. NASA's Environmental Research Aircraft Sensor Technology (ERAST) program produced such successful solar aircraft with names like Pathfinder, Centurion and Helios [12-13]. Recently, the Solar Impulse project has validated the prospect of perpetual flight by flying 24 hours non-stop in 2010 [14].

\section{CURRENT DESIGN OBJECTIVE}

Based on the literatures, we believe reliable broadband coverage using a pseudo-satellite on HAP can be achieved if the design objectives listed below can be satisfied. The design objectives are listed as such:

1. Cruise at $21,000 \mathrm{~m}$

2. Carry telecommunication payload of weight $100 \mathrm{~kg}$ (similar to HeliNet project [15-17].

3. Carry telecommunication payload with power requirement of $400 \mathrm{~W}$ (similar to HeliNet project [15-17]

Endurance of more than 24 hours (perpetual flight) using only solar power according to Malaysian solar irradiance model.

\section{CONCEPTUAL DESIGN ALGORITHM}

Quite a few literatures have been published that discussed the important issues pertaining to 
designing a solar aircraft $[14,18-22]$. This paper will follow and modify Noth's methodology [21] since it has a complete description and its algorithm has been shown as robust enough for many different design scenarios [23-27]. Nevertheless, all methodologies other than Noth's also rely on similar basic aerodynamics, structural and energy management principles, thus they should all converge to similar design solutions.

The first step to find the optimize design solutions for a perpetual solar aircraft is to consider the straight level flight or cruise. During the flight cruise, the lift is balanced by the weight which is constant since there would be no fuel burned. Equally, the thrust power is balanced by the total drag power. Incidentally, weight-lift and thrust-drag pairs are also related to each other. The total weight of the aircraft depends on the solar cells area and battery size whereby both are designed specifically to satisfy to the power requirement of the aircraft. Thus, to find the design solutions, we could start by assuming thrust and drag power equilibrium then work out the weight and lift of the aircraft or in the same token by first calculating total weight and lift before finding the corresponding power requirements. Aircraft weight optimization approach seems more reasonable since total weight is constant for both day and night flying, whereas optimizing using power approach introduced non-linearity early in the iterations since power available from the sun varies with time.

The total weight of solar aircraft $\left(m_{\text {tot }}\right)$ is represented as Equation (1). It is simply the summation of mass for avionics $\left(m_{a v c}\right)$, payload $\left(m_{p l d}\right)$, airframe $\left(m_{a f}\right)$, solar cells $\left(m_{s c}\right)$, maximum power point tracker (MPPT) $\left(m_{m p p t}\right)$, battery $\left(m_{\text {batt }}\right)$ and the whole propulsion system $\left(m_{\text {prop }}\right)$. This equation will be the master equation for optimization iteration.

$m_{\text {tot }} \cdot g=\left(m_{a v c}+m_{\text {pld }}+m_{a f}+m_{s c}+m_{\text {mppt }}+m_{\text {batt }}+m_{\text {prop }}\right) \cdot$

(1)The avionic system and payload weight can be considered fixed. For our current design, they are $20 \mathrm{~kg}$ and $100 \mathrm{~kg}$ respectively as per design objectives. Then, the airframe structure weight can be estimated from wing $\operatorname{span}(b)$ and aspect ratio $(\Lambda)$ by using Equation (2):

$m_{a f} \cdot g=0.044 b^{3.1} \Lambda^{-0.25}$

This relation is suggested by Noth [21] after he meticulously compiled 415 gliders (also called sailplane) into a database. He chose the lightest $5 \%$ out of all gliders and came up with 
the equation. The solar cells mass on the other hand is a product of its cell (including encapsulation) density constants $\left(k_{s c}+k_{\text {enc }}\right)$ and their surface area $\left(A_{s c}\right)$ such as in the Equation (3):

$m_{s c}=A_{s c}\left(k_{s c}+k_{\text {enc }}\right)$

To estimate the solar cells area $\left(A_{s c}\right)$, we first assume that the area is specifically chosen to obtain enough energy for day and night flying. Thus, the energy captured must equal to the energy required by the straight level flight, avionics and payload. Total energy captured from sun rise to sun set is the product of the area under the solar irradiance curve with efficiencies for weather $\left(\eta_{w t}\right)$, solar cells $\left(\eta_{s c}\right)$, airfoil camber $\left(\eta_{c b r}\right)$ and MPPT $\left(\eta_{m p p t}\right)$ such as in Equation (4). The energy required (Equation 5) is the time integration of power for cruise plus power for avionics and payload (Equation 6). Power for straight level cruise is well known [28] and given below as Equation (7). By inserting Equation (6) and (7) into Equation (5) and equating it to Equation (4), solar cells area can be calculated.

Energy captured by solar cells, $E_{\text {total }}=\frac{I_{\max } T_{\text {day }}}{\pi / 2} \eta_{w t} \eta_{s c} \eta_{c b r} \eta_{m p p t} A_{s c}$

Energy required, $E_{\text {tot }}=P_{\text {req }}\left(T_{\text {day }}+\frac{T_{\text {night }}}{\eta_{\text {chg }} \eta_{\text {dchg }}}\right)$

Power required, $P_{\text {req }}=\frac{P_{l v l}}{\eta_{c t r l} \eta_{\text {mot }} \eta_{g r b x} \eta_{p l r}}+\frac{P_{a v c}+P_{p l d}}{\eta_{b e c}}$

$P_{l v l}=\frac{C_{D}}{C_{L}^{1.5}}\left(m_{t o t} g\right)^{1.5}\left(\frac{2}{\rho S}\right)^{0.5}=\frac{C_{D}}{C_{L}^{\frac{3}{2}}}\left(m_{t o t} g\right)^{1.5}\left(\frac{2 \Lambda}{\rho b^{2}}\right)^{0.5}$

Mass of MPPT also varies proportionally to the total solar cells area. Is is the product of its density $\operatorname{constant}\left(k_{m p p t}\right)$ with maximum irradiance $\left(I_{\max }\right)$, solar cell efficiency $\left(\eta_{s c}\right)$, camber factor $\left(\eta_{c b r}\right)$, MPPT efficiency $\left(\eta_{m p p t}\right)$ and solar cells area $\left(A_{s c}\right)$. The relation is:

$$
m_{\text {mppt }}=k_{\text {mppt }} I_{\text {max }} \eta_{s c} \eta_{c b r} \eta_{m p p t} A_{s c}
$$

Mass of the battery varies linearly with the total energy that will be stored for the night time flight, which can be expressed as below:

$k_{\text {batt }} m_{\text {batt }}=\frac{T_{\text {night }}}{\eta_{\text {dchg }}} P_{\text {req }}$

$k_{\text {batt }}$ is the specific energy content or also called gravimetric energy density of the battery 
with the unit Watt Hour per kg. This constant is definitely one of the major, if not the only, limiting factor in designing a perpetual flying solar aircraft. The current state-of-the-art of Lithium-Ion polymer battery contains about $200 \mathrm{Wh} / \mathrm{kg}$ or less. This is obviously inadequate to store enough energy for night flying without being an excessive weight burden onto the aircraft. In 2010, the Zephyr7 solar aircraft achieve continuous flight by using Lithium-Sulfur battery with energy density of $350 \mathrm{Wh} / \mathrm{kg}$ even though the manufacturer claimed that it could go up to $600 \mathrm{Wh} / \mathrm{kg}$ [29]. Theoretically, Li-S battery could have up to $2500 \mathrm{Wh} / \mathrm{kg}$ [30] and this makes it attractive for manufacturers of electric vehicles since sulfur is a cheap and easily available material. However, they are still subjected to more research before it can be commercialized. Currently, a practical Li-S battery has been demonstrated [31] with a capacity of $1300 \mathrm{mAh} / \mathrm{g}$ which correlates to more than $2000 \mathrm{Wh} / \mathrm{kg}$ of energy density. Thus, for our current project, we believe that a battery with $700 \mathrm{Wh} / \mathrm{kg}$ of energy density would be available in the very near future.

For propulsion system, Noth [21] suggested that its mass can be modeled simply by the relationship below where $k_{\text {prop }}$ is the power to mass ratio of the propulsion system:

$m_{\text {prop }}=k_{\text {prop }} P_{l v l}$

\section{NUMERICAL SOLVER}

Optimization of design solutions was done using a script written in MATLAB environment. The script was set to vary the aspect ratio from 8 to 17 with a unit step increment. At every aspect ratio, the script will vary the wingspan from 10 to $100 \mathrm{~m}$ with 0.1 step increment and then find a minimum positive real number solutions of Equation (13) at every step. Engineering constants listed in Table 1 were utilized in the script. 
Table 1. Engineering constants needed for Equation (11) and their typical value

\begin{tabular}{|c|c|c|c|}
\hline Constants & Value & Unit & Notes \\
\hline 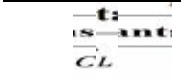 & 1.1 & - & Airfoil lift coefficient \\
\hline 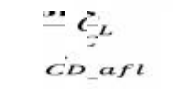 & 0.013 & - & Airfoil drag coefficient. To be added with parasitic and induced drag \\
\hline $\begin{array}{l}\text { CDaft } \\
\text { CD_par } \\
\text { Cart }\end{array}$ & 0.006 & - & Parasitic drag coefficient. To be added with airfoil and induced drag \\
\hline$\stackrel{\text { par }}{=}$ & 0.9 & - & Oswald's efficiency factor (assumed value) \\
\hline $\begin{array}{l}\text { De } \\
\text { pair }\end{array}$ & 0.0746 & $\mathrm{~kg} / \mathrm{m}^{3}$ & Density of air at $21 \mathrm{~km}$ altitude \\
\hline , & 950 & $\mathrm{~W} / \mathrm{m}^{2}$ & Maximum sun irradiance (typical value for Malaysia [32]) \\
\hline $\begin{array}{l}r_{\text {nax }} \\
\text { rebat } \\
\text { rebat }\end{array}$ & 700 & $\mathrm{Wh} / \mathrm{kg}$ & Energy density of LS battery (assumed value) \\
\hline $\begin{array}{l}m \text { mat } \\
c_{1} \\
\text { cesc }\end{array}$ & 0.32 & $\mathrm{~kg} / \mathrm{m}^{2}$ & Mass density of solar cells [21] \\
\hline 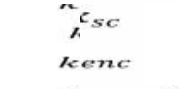 & 0.26 & $\mathrm{~kg} / \mathrm{m}^{2}$ & Mass density of encapsulation [21] \\
\hline $\begin{array}{rr}i_{\text {enc }} & 0 \\
\text { semppt } & 0.0\end{array}$ & 0.00042 & $\mathrm{~kg} / \mathrm{W}$ & Mass/power ratio of MPPT [21] \\
\hline $\begin{array}{l}\text { remppt } \\
\text { reprop } \\
\text { reprop }\end{array}$ & 0.008 & $\mathrm{~kg} / \mathrm{W}$ & Mass/power ratio of propulsion system [21] \\
\hline $\begin{array}{l}m_{\text {rop }} \\
c_{\text {riv }} \\
m a v\end{array}$ & 20 & $\mathrm{~kg}$ & Mass of avionics system [21] \\
\hline $\begin{array}{ll}\boldsymbol{r}^{\boldsymbol{p}_{\text {pav }}} & 20 \\
\boldsymbol{m}^{\text {mplid }} & 100\end{array}$ & 100 & $\mathrm{~kg}$ & Mass of telecommunication payload [21] \\
\hline $\begin{array}{l}\text { "ipla } \\
\text { npec }\end{array}$ & 0.65 & - & Efficiency of step-down converter [21] \\
\hline $\begin{array}{l}{ }_{\text {eec }} \\
\eta^{\text {ent }} \\
\eta^{w t}\end{array}$ & 1 & - & $\begin{array}{l}\text { Weather factor which reduces the energy captured. Value of } 1 \text { is clear } \\
\text { sky(assumed value) }\end{array}$ \\
\hline nse & 0.169 & - & Efficiency of solar cells [21] \\
\hline $\begin{array}{l}l_{s c} \\
n c b r\end{array}$ & 0.90 & - & Efficiency of curved solar panels [21] \\
\hline $\begin{array}{l}n^{c b r} \\
n c h g\end{array}$ & 0.95 & - & Efficiency of battery charge [21] \\
\hline $\begin{array}{ll}"{ }^{c h g} & 0 . \\
n^{c t r r l} & 0 .\end{array}$ & 0.95 & - & Efficiency of motor controller [21] \\
\hline $\begin{array}{l}\text { lctrret } \\
\text { ndehng }\end{array}$ & 0.95 & - & Efficiency of battery discharge [21] \\
\hline $\begin{array}{l}\text { "tchg } \\
\text { 7echorb } \\
\text { ngra }\end{array}$ & 0.97 & - & Efficiency of gearbox [21] \\
\hline $\begin{array}{l}\dddot{n}^{g r b} \\
n^{\text {mot }}\end{array}$ & 0.85 & - & Efficiency of motor [21] \\
\hline 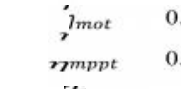 & 0.97 & - & Efficiency of MPPT [21] \\
\hline $\begin{array}{l}\text { "rppt } \\
\text { 'npplr } \\
\text { nplr }\end{array}$ & 0.85 & - & Efficiency of propeller [21] \\
\hline $\begin{array}{l}\text { ptr } \\
\text { Fav }\end{array}$ & 100 & $\mathrm{~W}$ & Power for avionics (based from HeliNet project) \\
\hline 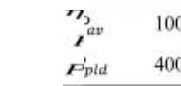 & 400 & $\mathrm{~W}$ & Power for telecommunication payload (based from HeliNet project) \\
\hline
\end{tabular}




\section{PRELIMINARY DESIGN SOLUTION}

It was found that, there could be no close form solution of the equation with the current design objectives. Of course, reducing the payload mass to $50 \mathrm{~kg}$ and its power to $100 \mathrm{~W}$ will yield results by the algorithm but such exercise would be unrealistic since a practical telecommunication device would be much heavier and require more power. Thus, a modification to the aircraft structure must be made. We propose a hybrid concept combining the aircraft with lighter-than-air technology to assist in carrying the load.

\section{MODIFIED NUMERICAL SOLVER FOR HYBRID AIR-VEHICLE CONCEPT}

Abundant of literatures can be found on the inflatable wing/aircraft technology. Our design team believes that it is possible to construct an inflatable aircraft using high strength fiber materials such as Kevlar, Vectran or glass fibers. Such aircraft would then be rigidized in order to give the freedom of varying the internal pressure of the lighter-than-air gas such as Helium. Similar idea has been discussed by [13]. Construction of such aircraft will be discussed in later sections. By assuming that total fuselage $+\operatorname{wing} \operatorname{volume}(V)$ are linked to aircraft wingspan and aspect ratio and that the internal pressure of Helium is set to atmospheric pressure at $21 \mathrm{~km}$ altitude, we could modify equation to become:

$g \cdot m_{\text {lift }}=g \cdot \mathbb{A}(b, \Lambda) m_{\text {lift }}^{1.5}+g \cdot \mathbb{B}(b, \Lambda)-$ buoyancy force

$g \cdot m_{\text {lift }}=g \cdot \mathbb{A}(b, \Lambda) m_{\text {lift }}^{1.5}+g \cdot \mathbb{B}(b, \Lambda)-g \cdot\left(\rho_{\text {air }}-\rho_{\text {helium }}\right) V$

$m_{\text {lift }}=\mathbb{A}(b, \Lambda) m_{\text {lift }}{ }^{1.5}+\mathbb{B}(b, \Lambda)-\mathbb{C}(b, \Lambda)(11)$

The new variable $m_{\text {lift }}$ is the weight of the aircraft that is carried by the lift from wing. It is the difference between the total weight minus the buoyancy force. In another word, it simply means the effective weight experienced by the aircraft wing after buoyancy force has been considered. By simple substitution of $Z=m_{\text {lift }}{ }^{0.5}$

$\mathbb{A}(b, \Lambda) Z^{3}-Z^{2}+\mathbb{B}(b, \Lambda)-\mathbb{C}(b, \Lambda)=0$

New optimization routine was written in MATLAB to solve for the Equation (12). The engineering constants in Table 1 were kept for this new routine. 


\section{NEW DESIGN SOLUTION}

Possible solutions for $m_{\text {lift }}$ are plotted against wing span and aspect ratio (range from 8-17) (see Fig. 2). Choosing higher aspect ratio at constant wing span would reduce the burden of the wing whereby the weight needed to be carried by the wing will be less. However, very high aspect ratio wing would not be very suitable for inflatable wing design such as ours. The wing would be very flexible and can experience excessive aero-elastic problems. Thus, for our current design we choose wing span of $50 \mathrm{~m}$ and aspect ratio of 13 . The chosen aspect ratio is comparable than Lockheed's U-2 spy-plane which has similar altitude to ours.

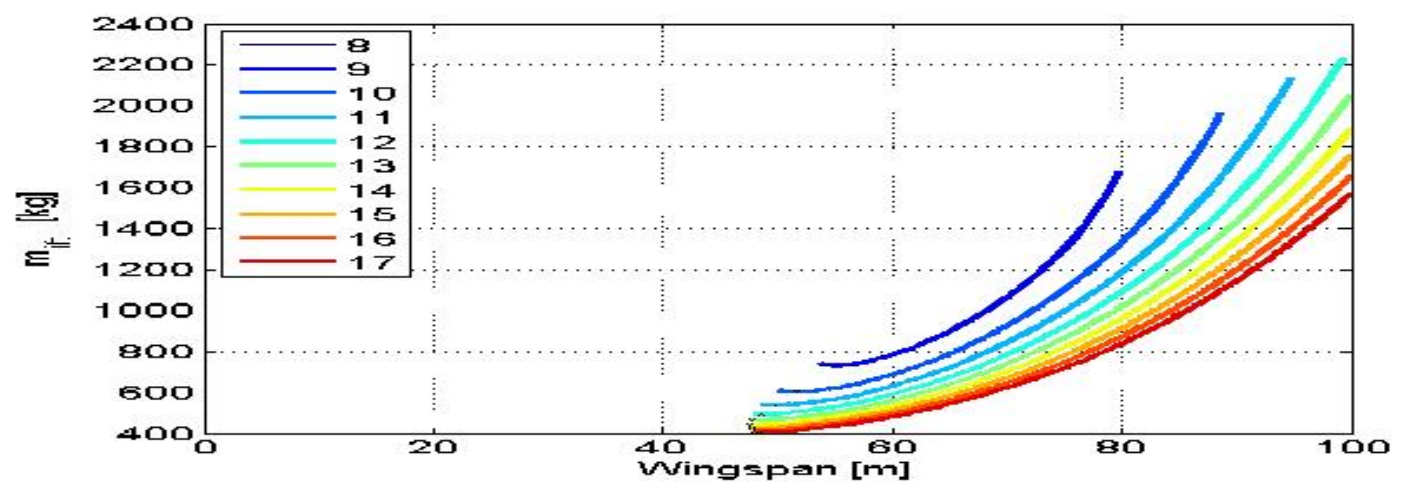

Fig.2. Possible range of wing span and aspect ratio that will give solutions to Equation (12) The MATLAB routine automatically calculates other specifications based on previously listed equations using our chosen aspect ratio and wing span. All specifications are listed in Table 2.

Table 2. Specifications of aircraft that will satisfy our design objectives

\begin{tabular}{|c|c|}
\hline Aspect Ratio, $\Lambda$ & 13 \\
\hline Wing Span, ${ }_{b}$ & $50 \mathrm{~m}$ \\
\hline Effective Weight, ' maift & $4 \quad 469 \mathrm{~kg}$ \\
\hline Battery Weight, ${ }_{m b a t}^{m^{2 i f t}}$ & $144.2 \mathrm{~kg}$ \\
\hline Total weight, $\begin{array}{c}n^{n_{\text {bat }}} \\
m \text { mot }\end{array}$ & $600.44 \mathrm{~kg}$ \\
\hline Volume for Helium, & $2103.81 \mathrm{~m}^{3}$ \\
\hline Wing Area, $\stackrel{s}{s}$ & $192.31 \mathrm{~m}^{2}$ \\
\hline $\begin{array}{c}\text { Solar Cells Area, asc } \\
\text { cens }\end{array}$ & $167.94 \mathrm{~m}^{2}$ \\
\hline Max Ba ttery Capacity, & $100940 \mathrm{Wh}$ \\
\hline \multicolumn{2}{|l|}{$E_{\max -b a t}$} \\
\hline Cruise Velocity, & $24.2 \mathrm{~m} / \mathrm{s}$ \\
\hline
\end{tabular}




\section{DESIGN VALIDATION: WEIGHT BALANCE ANALYSIS}

To check the validity of the design solutions, we first subject it to weight balance analysis. The aircraft must have zero or negligible residue after the total weight minus the sum of lift and buoyancy force. The lift can be calculated from standard lift equations where:

Lift $=0.5 C_{L} \rho_{\text {air }} S v^{2}=0.5 * 1.1 * 0.0746 * 192.31 * 24.2^{2}=4620.98 \mathrm{~N}$

The buoyancy force can be calculated using:

Buoyancy $=g\left(\rho_{\text {air }}-\rho_{\text {helium }}\right) \mathrm{Vol}=9.81 *(0.0746-0.0121) * 2103.81=1289.90 \mathrm{~N}$

To balance downward weight force and total upward force:

Weight $-($ lift + buoyancy $)=600.44 * 9.81-(4620.98+1289.9)=-19.58 \mathrm{~N}$

The residue of $-19.58 \mathrm{~N}$ is negligible since it is about $0.3 \%$ of the total weight of the aircraft.

Thus based on the weight balance, we could confirm the validity of the design solutions suggested by our MATLAB routine.

\section{DESIGN VALIDATION: POWER BALANCE ANALYSIS}

To further validate the design solutions, we perform a power balance check where we model the aircraft flying in 48 hours with fluctuating solar irradiance. The objectives are to investigate whether the solar cells could capture and whether the battery could store, enough energy for night flying mission. The whole aircraft system can be modeled in Simulink and its graphical representation is shown in Fig. 3. Firstly, we modeled the solar irradiance using a sine wave. Although seem simplistic, Noth demonstrated that sine wave could closely represent hourly irradiance model [21]. We assume that the irradiance is positive from 7 am to $7 \mathrm{pm}$ and zero at other times. The power captured by solar cells depends on its efficiency and the efficiency of MPPT. The power required to operate the aircraft is the sum of power for cruise, avionics and payload. For this current model, we assume that the aircraft only cruise at a constant altitude and constant speed.

For future study, the aircraft can be modeled with moderate climb during the day before descend to lower altitude at night in order to convert surplus solar energy into potential energy. The battery manager was modeled such as to start discharging the battery whenever the power supplied from solar is less than the power required for aircraft operations. The power manager 
would also start battery charging only when the battery current energy level is below maximum and there is surplus in solar power. The time domain is 48 hours starting at 7 am. Initially, the battery was given $10,000 \mathrm{Wh}$ of energy level. The plots for power and energy against time are given in Fig. 4 and 5.

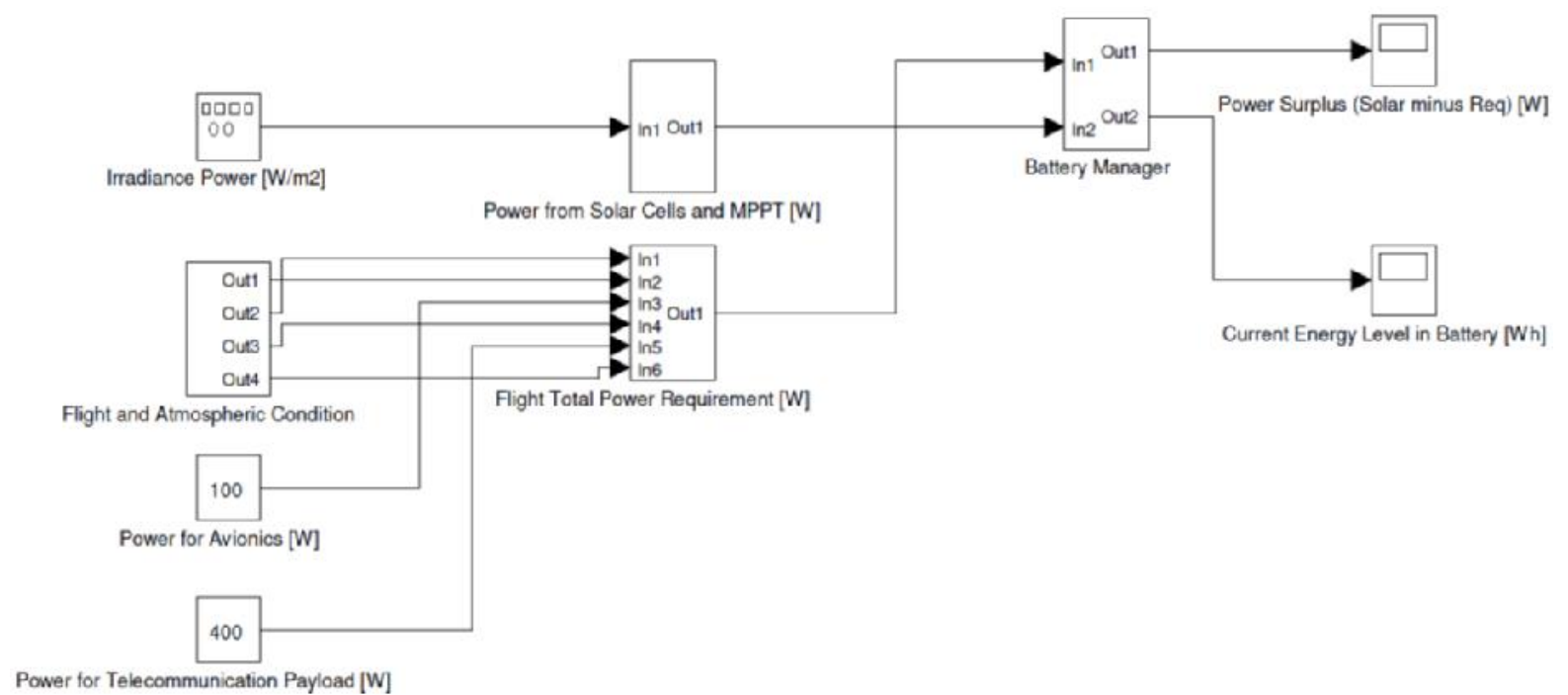

Fig.3. Power system modeled in Simulink

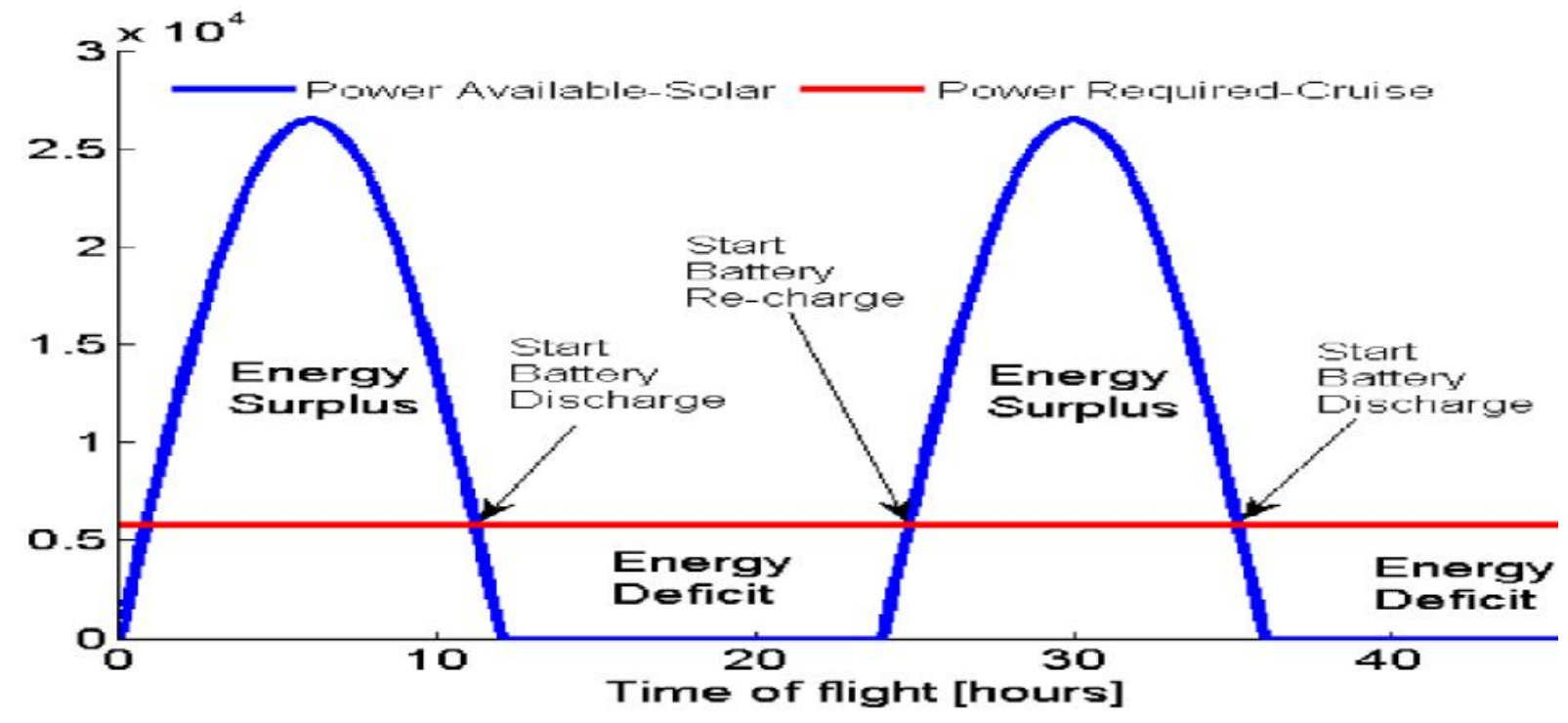

Fig. 4.Plot of solar power and power required in 48 hours 


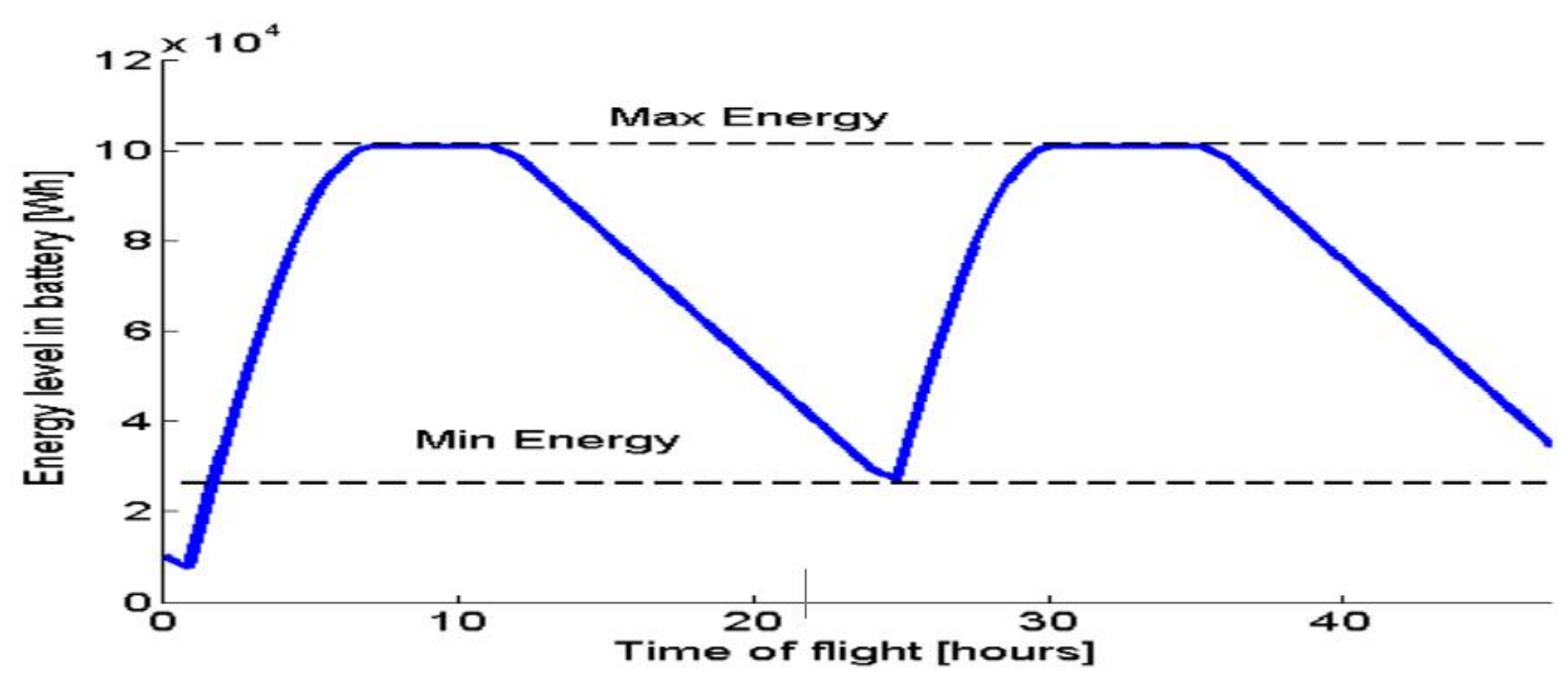

Fig.5. Plot of battery energy level in 48 hours

From Fig. 4, we could see that at 7 am, the power from the solar was not enough thus some battery power was needed to cover the gap. This lasted for almost an hour before there is a surplus in power where the initial battery level has dropped $25 \%$ (see Fig. 5). The battery manager allowed for battery recharge whenever there is surplus in power and it would take about 6 hours to fully charge it (see Fig. 5).

The battery would stay at the maximum energy level of $101 \mathrm{kWh}$ for about 4 hours before deficit in power started at about $6 \mathrm{pm}$. The battery continues its discharge until almost at 8 am on the next day, dropping its energy to minimum level of $27 \mathrm{kWh}$. The battery would then be fully charged again in less than 6 hours before deficit in power requires it to support the aircraft operation once again. This cycle of recharge and discharge between minimum to maximum energy would continue indefinitely if the simulation was given a bigger time frame. This proves that our design solutions indeed satisfy the mission requirements of perpetual flying.

\section{SYSTEM RELIABILITY ANALYSIS}

The power and energy analysis done in previous section has a big uncertainty in it since they depend on assumed values listed in the engineering constant in Table 1. Among the parameters with large uncertainty are the maximum irradiance $\left(I_{\max }\right)$ and solar cells efficiency $\left(\eta_{s c}\right)$. We use $950 \mathrm{~W} / \mathrm{m}^{2}$ as the maximum irradiance of Malaysian atmosphere at $21 \mathrm{~km}$ altitude. However, there is no published literature yet that can give clear indications of 
maximum irradiance value at that altitude. Few literatures only measured the ground level irradiance on clear sky conditions and the values are around $968 \mathrm{~W} / \mathrm{m}^{2}$ as monthly average [33]. For our design, we conservatively assumed that $I_{\max }$ is about $950 \mathrm{~W} / \mathrm{m}^{2}$, a low figure considering that $I_{\max }$ for a clear day should increase with altitude.

Nevertheless, $I_{\max }$ at an altitude increase and decrease depending on earth position on its elliptical orbit around the sun [34]. $I_{\max }$ also depends on various solar activities and phenomenon, which are said to change periodically every 11 years [35-36]. The ozone layer which is located in the stratosphere (our design altitude) are known to absorb part of the solar spectrum which would also decrease the overall solar energy received [37], and the ozone concentration itself is highly varied [38]. The change of the dominant spectrum in sunlight will affects the performance of solar cells as reported by [39]. Various kinds of aerosols polluting the atmosphere have their peak concentration around $20 \mathrm{~km}$ altitude. They reduce the energy in sunlight by backscatter and absorption as reported by [27, 40]. Solar cells efficiency $\left(\eta_{s c}\right)$ also varies by large degrees depending mostly on their operating temperature [33] and just like the ozone layer concentration, stratospheric temperature above Malaysia is highly varied [38]. Icing problem which may or may not occur depending mainly on the temperature could reduce the energy received by the solar panels.

Apart from randomness in the energy collected by the solar panels such as discussed above, we must also anticipate that the energy required by cruise may not be as constant as we initially assumed. This is due mainly to the gust phenomena which should be less in the stratospheric altitude but still significant nevertheless. In one NASA report, it could induce $0.5 \mathrm{G}$ of impulse with occurrence frequency of about $1 \%$ of the flight time [34]. Besidesthat, the stratosphere typically has wind current that follow planetary-scale Rossby wave [41]. However, the magnitude of the velocity at $21 \mathrm{~km}$ altitude above Malaysia is highly fluctuated [38]. If the wind movement is at different direction to cruise, then the aircraft would need higher power to maintain its speed relative to the ground. Conversely, if the wind is at similar direction to cruise then the aircraft would save energy.

To further validate our design, we must demonstrate the reliability of our solar energy harvesting system in fulfilling the total energy needed by cruise and flight mission. One way 
to convincingly measure reliability of a system plagued by randomness in many of its key parameter is to use a Monte Carlo simulation. Such method has been demonstrated by reference [42-44].

Monte Carlo simulation is a statistical tool that incorporate stochastic characters in a deterministic mathematical model [45]. In our case, we can easily calculate total energy collected by the solar panels using the Equation (13). We could also easily calculate the total energy consumption due to cruise flight, avionics and telecommunication payload using Equation (14).

Tot. solar energy collected in 48hours $=\left(I_{\max } A_{s c} \eta_{s c} \eta_{c b r} \eta_{m p p t}\right) \cdot \frac{12}{\frac{\pi}{2}} \cdot 2$

Tot. energy consumed in 48hours $=\left(0.5 C_{D} \rho S V^{3}+500\right) * 48$

We must recognize that in both equations, there are ranges of output values that can be attributed to their input parameters. We could for example produce three calculations; the base case, worst case and best case. Hitherto, this will produce a misguided prediction since the best and worst case could have very low probability of actually happening. Using Monte Carlo simulation, we could produce ranges of possible outcome along with their probability of actually happening. This is done by first identifying the distribution, if any, in the input parameters which in our case is the $I_{\max }$, solar cells efficiency and velocity of flight.

For our simple analysis, we assume that $I_{\max }$ will vary by $\pm 20 \%$, solar cells efficiency by $\pm 5 \%$ and flight velocity by $\pm 7 \%$. For best case value, we calculate the balance of energy collected less the energy required when $I_{\max }$ is $1140 \mathrm{~W} / \mathrm{m}^{2}$, solar cells efficiency is $24 \%$ and flight velocity is $17 \mathrm{~m} / \mathrm{s}$. The worst situation for energy balance is when $I_{\max }$ is $760 \mathrm{~W} / \mathrm{m}^{2}$, solar cells efficiency is 0.14 and flight velocity is $31 \mathrm{~m} / \mathrm{s}$. Using the balance energy value of best and worst case scenario, we can calculate the overall representative of standard deviation $(\sigma)$ and average of output. We then produced random number prediction of each variables using Microsoft Excel's rand() command. Unique output values are produced for each iteration. The number of iteration $(N)$ required is calculated using [46]:

$\sqrt{N}=3 \sigma / \varepsilon$

Total error $(\varepsilon)$ is calculated using our estimated average(i.e. the average of best and worst case) 
divided by the required error. For the current analysis, we conservatively say that we want a correct prediction within $5 \%$ of error. Thus, total error is:

$\varepsilon=($ estimated average $) / 0.5$

This will result in the minimum iteration required of about 59,606 times. Thus we run our iteration at 60,000 times and the frequency results are plotted in Fig. 6. The plot in Fig. 5 shows the frequency of different output of total energy collected by the solar cells less the energy consumed for cruise, avionics and payload in the duration of 48 hours. It can be seen that there is significant probability, about $25 \%$ of all cases of the flight having negative balance which means that the energy consumed during 48 hours is more than the total energy collected. Nevertheless, there are actually less than $10 \%$ occurrences of energy deficit cases where the deficit has higher magnitude than the maximum battery capacity. This means that many energy deficit cases can be solved by initially charging the battery to the maximum before the mission begins. We did not incorporate the initial energy charge level in either Equation (16) or (17); whereas we as the designer have the freedom to specify the initial

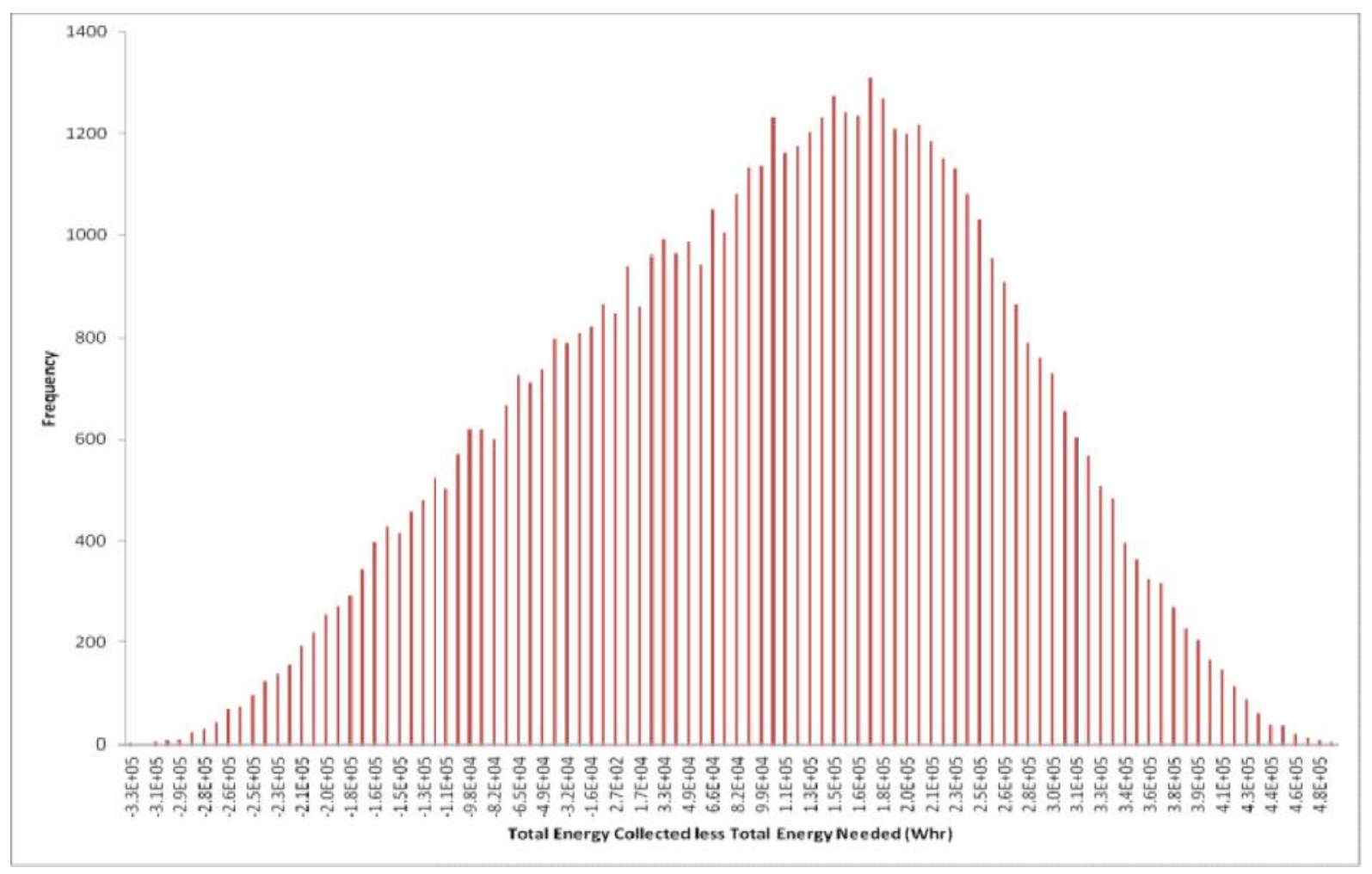

charge.

Fig.6. Frequency chart of possible output of net energy

The most likely scenario is the average of all possible output where the total energy collected 
will larger than the energy consumed by a margin of about 102,000 Wh. We can be confident with our design since the energy collected will be in surplus or at least at similar level to energy consumed at about $90 \%$ of the times. The new standard deviation can be calculated from all samples. The final absolute error can be calculated using the new standard deviation and using equation above. This absolute error is about $1.8 \%$.

An interesting question to ponder is what will happen to the aircraft if for any reason the solar did not provide enough energy and the battery ran out of power at the same time? The telecommunication payload will cease to function of course, but what about the aircraft? Well, the since the hypothetical scenario says there is no power neither from solar nor backup battery, the aircraft propeller will stop moving. Given that lift is proportional to cruise velocity squared, the aircraft will lose all of its lift except the buoyancy force will still be there.

Thus, we arrive at an interesting scenario where the aircraft will slowly descend but will never crash to the ground, assuming we maintain the internal pressure of helium gas inside the hybrid aircraft. We can calculate the altitude at which our unpowered hybrid aircraft will hover by relating buoyancy to weight. This is illustrated by calculation below:

Buoyancy $=9.81 *\left(\rho_{\text {air }}-0.0121\right) * 2103.81=$ Weight $=600.44 * 9.81$

From the calculation, we found that the density of air $\rho_{\text {air }}$ is $0.298 \mathrm{~kg} / \mathrm{m} 3$ and this translates into an altitude of 12,278 $\mathrm{m}$ above sea level. Thus we are confident with the crashworthiness of our hybrid aircraft. The unpowered aircraft could hover at its minimum altitude before it collects enough energy to climb back to design altitude. On the other hand, by way of manipulating the pressure inside the hybrid aircraft, it could even descend further if required.

\section{PRELIMINARY SKETCHES}

The early sketches of our current design are given in the Fig. 7. To achieve the large volume requirement, we looked up to Airbus A380 as a shape example. We opted for twin fuselage design to reduce the side cross-sectional area thus reducing the probability of side drift. The length of the fuselage is $48 \mathrm{~m}$ which is only slightly shorter than its wing span.

The total volume for wing and fuselage is more than 2700 cubic meter providing ample room 
for Helium and other equipment. The fuselage length could be extended longer if the need arises (for example, to accommodate larger payload) because it is common for passenger aircraft, for which our design refers to have fuselage longer than the wingspan. NACA 2421 was chosen for the airfoil because it has a thick profile of $21 \%$ of chord and airfoil drag coefficient of 0.013 when its lift coefficient is 1.1 , just like we assumed during the optimization process. The airfoil was set at $9^{\circ}$ angle-of-attack (AoA), so as to achieve the required lift coefficient. The airfoil has stall angle of $15^{\circ}$, which leave sufficient margin from our cruise AoA. Taper ratio was given as such to maximize the wing chord and thickness at root in order to have more structural integrity. The leading edge and trailing edge angle sweep was given arbitrarily and would be decided later after aerodynamic analysis is performed. Similarly, the tail size is given capriciously without proper regards to flight stability analysis which will be done later.
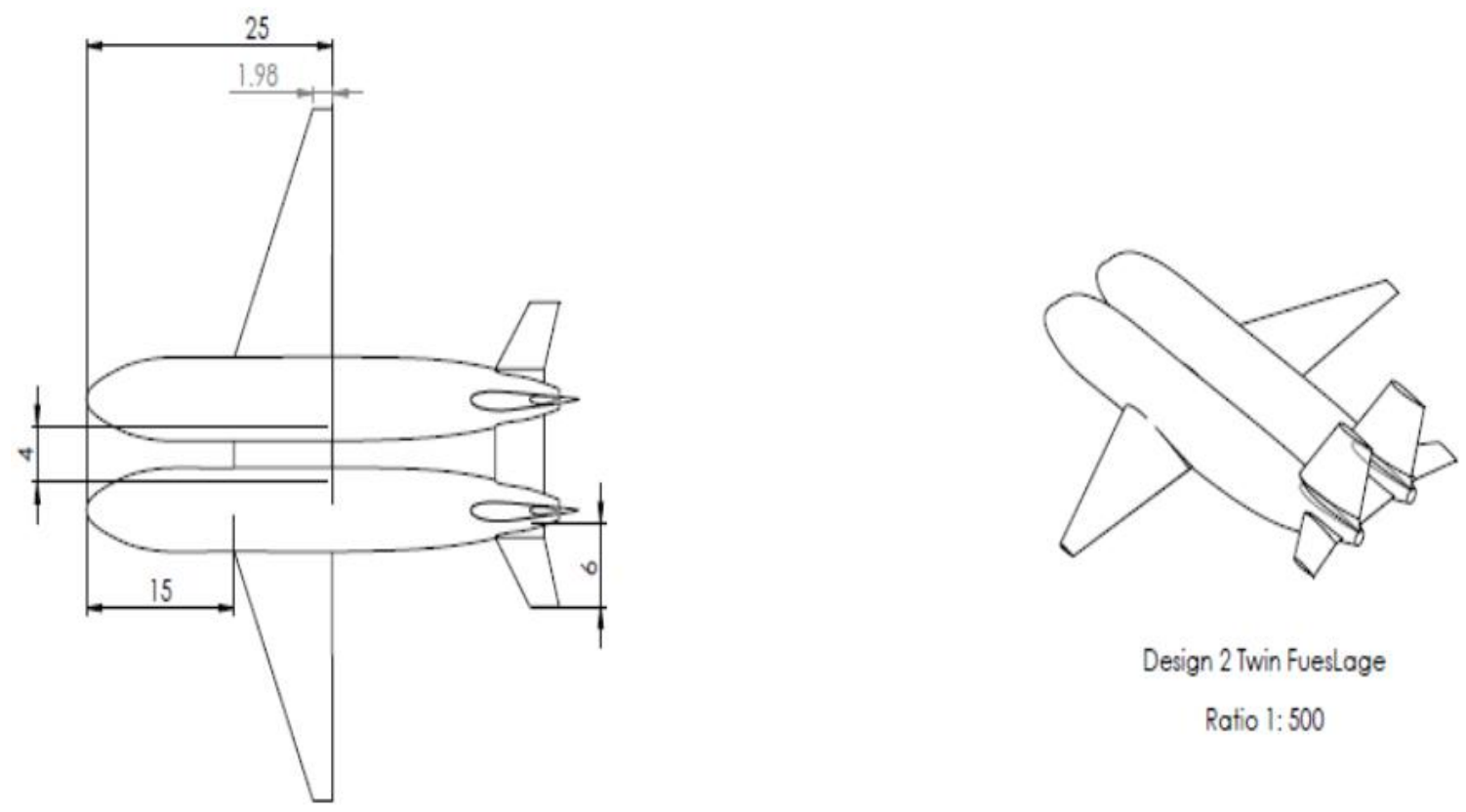

Design 2 Twin FuesLage

Ratio 1: 500
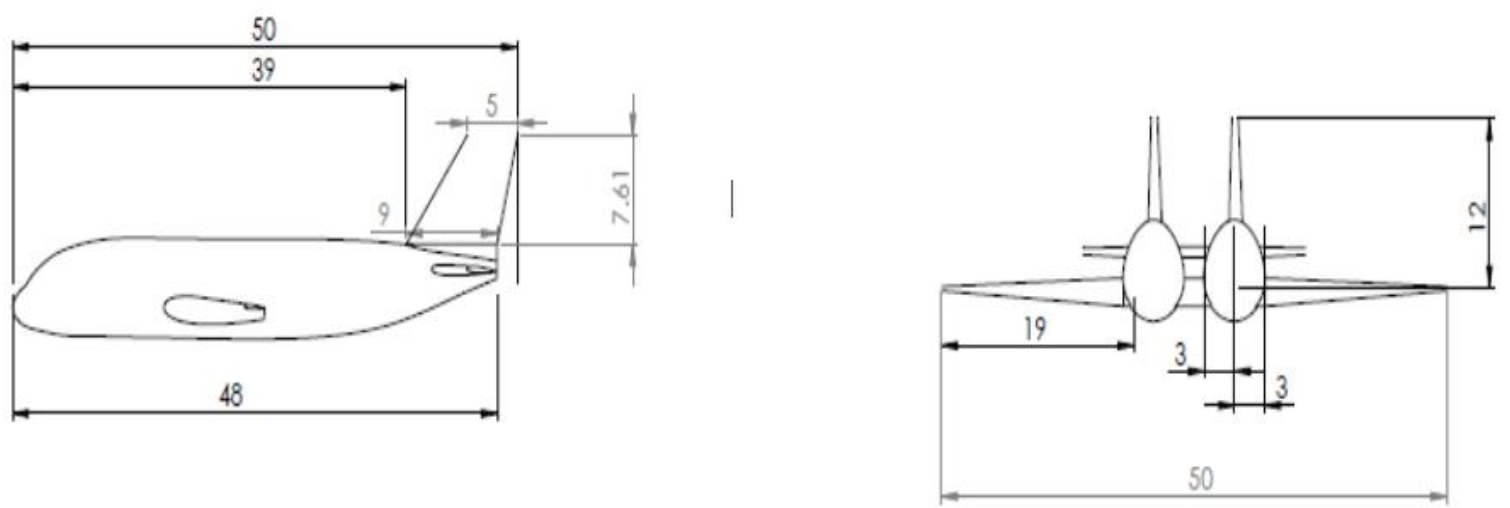

Fig.7. Preliminary sketches for our design dimensions in meter 


\section{MATERIAL AND STRUCTURE}

After we have tackled the mathematical foundations of our design, we need to address the obvious problem of how to actually build a hybrid air vehicle such as ours. Inflatable wing and fuselage is not actually too far fetch an idea because in 1950s, Goodyear unveiled their Inflatoplane, a fully stowable aircraft made of two rubber-type materials connected with nylon mesh thread. The idea of inflatable aircraft structure goes back to 1930s, where Taylor MacDaniels experimented and patented the concept of rubber glider [47].

The effort to study and further develop the inflatable wing concept came in the mid-2000s, where the group in the University of Kentucky along with their industrial partner ILC Dover pursued the Big Blue project [47-48]. The project aimed to develop inflatable wing aircraft that could operate in low density flight applications such as Mars aerial explorer [48-49]. Due to Mars low-density, an aerial explorer needs to have very large wing span thus causing a problem to carry the aircraft from earth to the planet. Thus, foldable inflatable wing is needed to fit the aircraft into a suitable spacecraft. Using inflatable wing aircraft on Mars also have the added advantage of allowing for Helium to be used to aid the lifting of the aircraft thus reducing the need for exceptionally long wing span. The BIG BLUE project has also demonstrated the concept of using the ultraviolet (UV) curing to rigidize their flexible E-glass inflatable wing [48-50]. They wanted to rigidize their inflatable wing to reduce the need for maintaining a high pressure inside the wing. We propose to use a similar technique for our inflatable aircraft where our aircraft would be made from high strength fabric materials, and then cured with (UV) to allow for freedom in maintaining internal pressure independent from external atmospheric pressure.

\section{CONCLUSION}

Based from our mathematical analysis, the main problem that hindered the development of a perpetual HAP aircraft for pseudo satellite application is finding the delicate balance between energy that can be stored for night flying and the total weight of the aircraft. We then proposed for structural modifications of the aircraft concept that we want to design. We suppose that lighter-than-air technology can be used in hybrid with the conventional lift from 
the wing. Thus, we modify the original total weight equation to include buoyancy force which will be solved numerically. Our solver indeed found a tractable range of solutions allowing us the flexibility to choose suitable wing span and aspect ratio. We chose $50 \mathrm{~m}$ wing span and aspect ratio of 13 from which the code would then compute other specifications of the aircraft such as cruise speed, total weight, volume for Helium, solar cells area and others. We did a power balance check and we found that the battery could store enough energy to cover the flight, avionics and payload power every time the solar power was in deficit. Reliability of solar energy to power the whole mission is demonstrated by Monte Carlo simulation.

\section{ACKNOWLEDGEMENTS}

This work was supported by National Defence University of Malaysia (NDUM) internal grant scheme.

\section{REFERENCES}

[1] Baldwin M P, Dunkerton T J. The solar cycle and stratosphere-troposphere dynamical coupling. Journal of Atmospheric and Solar-Terrestrial Physics, 2005, 67(1):71-82

[2] Beer J. Solar variability and climate change. Memorie-SocietaAstronomicaltaliana. 2005, 76(4):751-754

[3] Bhatt M R. Solar power unmanned aerial vehicle: High altitude long endurance applications (HALE-SPUAV). Master thesis, California: San Jose State University, 2012

[4] Bolkcom C. Potential military use of airships and aerostats. CRS Report for Congress, Washington, D.C.: Federation of Atomic Scientists, 2006

[5] Boucher R J. Sunrise, the world's first solar-powered airplane. Journal of Aircraft,1985, 22(10):840-846

[6] Brandt S A, Gilliam F T. Design analysis methodology for solar-powered aircraft. Journal of Aircraft, 1995, 32(4):703-709

[7] B er K. The solar spectrum at typical clear weather days. Solar Energy,1977, 19(5):525-538

[8] Cadogan D, Graham W, Smith T. Inflatable and rigidizable wings for unmanned aerial 
vehicles. In 2nd AIAA “Unmanned Unlimited” Systems, Technologies, and Operations,2003, pp. $15-18$

[9] Capanina D N. D12: Report on delivering broadband for all from aerial platforms including commercial and technical risk assessments. Document Number CAP-D12-WP12-BT-PUB-01, York, 2004

[10] Colozza A, Dolce J. Initial feasibility assessment of a high altitude long endurance airship. Technical Report NASA/CR-2003-212724, E-14248, Ohio: Analex Corporation, 2003 [11] Daut I, Irwanto M, Irwan Y, Gomesh N, Ahmad N. Clear sky global solar irradiance on tilt angles of photovoltaic module in Perlis, Northern Malaysia. In International Conference on Electrical, Control and Computer Engineering, 2011, pp. 445-450

[12] Deaton J D. High altitude platforms for disaster recovery: Capabilities, strategies, and techniques for emergency telecommunications. EURASIP Journal on Wireless Communications and Networking, 2008, 2008:1-8

[13] Edge H L, Brown A, Collins J. Pressurized structures-based unmanned aerial vehicle research. Journal of Intelligent and Robotic Systems, 2012, 65(1):603-620

[14] Ehernberger L, Donohue C, TeetsJr E H. A review of solar-powered aircraft flight activity at the Pacific missile range test facility, Kauai, Hawaii. In 11h AMS Conference on Aviation, Range, and Aerospace Meteorology, 2004, pp. 1-7

[15] Everaerts J. The use of unmanned aerial vehicles (UAVs) for remote sensing and mapping. International Archives of the Photogrammetry, Remote Sensing and Spatial Information Sciences, 2008, 37:1187-1192

[16] Evers S,Nazar L F. New approaches for high energy density lithium-sulfur battery cathodes. Accounts of Chemical Research,2012, 46(5):1135-1143

[17] Filippone A. Flight performance of fixed and rotary wing aircraft. Amsterdam: Elsevier, 2006

[18] Gao, X Z, Hou Z X, Guo Z, Chen X Q. Reviews of methods to extract and store energy for solar-powered aircraft. Renewable and Sustainable Energy Reviews, 2015, 44:96-108 [19] Hall D W, Fortenbach C D, Dimiceli E V, Parks R W. A preliminary study of solar powered aircraft and associated power trains. Technical Report NASA-CR-3699, NAS 
1.26:3699, California: Lockheed Missiles and Space Corporation, 1983

[20] Hartney C J.Design of a small solar-powered unmanned aerial vehicle.Master thesis, California: San José State University, 2011

[21] Honda T, Chen H Q, Chan K Y, Yang M C. Propagating uncertainty in solar panel performance for life cycle modeling in early stage design. In AAAI Spring Symposium Series, 2011, pp. 66-73

[22] Hood L L. Effects of solar UV variability on the stratosphere. In J. M. Pap, P. Fox, C. Frohlich, H. S. Hudson, J. Kuhn, J. McCormack, G. North, W. Sprigg, \& S. T. Wu (Eds.), Solar variability and its effects on climate.Washington DC: American Geophysical Union, 2003, pp. 283-303

[23] Jamison L, Sommer G S,PorcheI R.High-altitude airships for the future force army.Technical report, California: Rand Arroyo Center Santa Monica, 2005

[24] Leutenegger S, Jabas M,Siegwart R Y. Solar airplane conceptual design and performance estimation. Journal of Intelligent and Robotic Systems,2011, 61(1):545-561

[25] Liang X, Hart C, Pang Q, Garsuch A, Weiss T,Nazar L F. A highly efficient polysulfide mediator for lithium-sulfur batteries. Nature Communications, 2015, 6:1-8

[26] Malaver R J A. Development of gas sensing technology for ground and airborne applications powered by solar energy: methodology and experimental results. Phd thesis, Brisbane: Queensland University of Technology, 2014

[27] Marggraf W, Griggs M. Aircraft measurements and calculations of the total downward flux of solar radiation as a function of altitude. Journal of the Atmospheric Sciences, 1969, 26(3):469-477

[28] Metropolis N,Ulam S. The Monte Carlo method. Journal of the American Statistical Association, 1949, 44(247):335-341

[29] Navarro R. ER-2: Flying laboratory for earth science studies. In 32nd International Symposium on Remote Sensing of Environment, 2007, pp. 1-4

[30] Noll T E, Ishmael S D, Henwood B, Perez-Davis, M E, Tiffany G C, Madura J, Gaier M, Brown J M,Wierzbanowski T. Technical findings, lessons learned, and recommendations resulting from the Helios prototype vehicle mishap.In UAV Design Processes / Design 
Criteria for Structures, 2007, pp. 1-18

[31] Norris R K, Pulliam W J. Historical perspective on inflatable wing structures. In 50th AIAA/ASME/ASCE/AHS/ASC Structures, Structural Dynamics, and Materials Conference, 2009, pp. 4-7

[32] Noth A. Design of solar powered airplanes for continuous flight.Phd thesis, Switzerland: Swiss Federal Institute of Technology in Zurich,2008

[33] Noth A, Engel M W,Siegwart R. Flying solo and solar to Mars. IEEE Robotics and Automation Magazine,2006, 13(3):44-52

[34] Noth A, Engel W,Siegwart R. Design of an ultra-lightweight autonomous solar airplane for continuous flight. In P. Corke, \& S. Sukkariah (Eds.), Field and service robotics.Berlin: Springer, 2006, pp. 441-452

[35] Ollero A, Merino L. Unmanned aerial vehicles as tools for forest-fire fighting. Forest Ecology and Management,2006, 234(1):1-11

[36] Pinkney M F, Hampel D,DiPierro S. Unmanned aerial vehicle (UAV) communications relay. In IEEE Military Communications Conference, 1996, pp. 47-51

[37] Popescu D E, Popescu C, Gabor G. Monte Carlo simulation using excel for predicting reliability of a geothermal plant. In International Geothermal Conference,2003, pp. 7-12

[38] Raychaudhuri S. Introduction to Monte Carlo simulation. In Winter Simulation Conference, 2008, pp. 91-100

[39] Ross H. Fly around the world with a solar powered airplane. Power, 2008, 1(8):1-9

[40] Smith S W, Jacob J D, Jones R J, Scarborough S E,Cadogan D P. A high-altitude test of inflatable wings for low-density flight applications. In 7th AIAA Gossamer Spacecraft Forum, 2006, pp. 1-13

[41] Stephens H. Near-space. Air Force Magazine. 2005, 88(7):36-40

[42] Thekaekara M P. Solar irradiance: Total and spectral and its possible variations. Applied Optics, 1976, 15(4):915-920

[43] Thornton J, Grace D, Spillard C, Konefal T,Tozer T. Broadband communications from a high-altitude platform: The European HeliNetprogramme. Electronics and Communication Engineering Journal. 2001, 13(3):138-144 
[44] Tozer T, Grace D, Thompson J,Baynham P. UAVs and HAPs-potential convergence for military communications. In IEE Colloquium on Military Satellite Communications, 2000, pp. 10-21

[45] Tozer T C, Grace D. High-altitude platforms for wireless communications. Electronics and Communication Engineering Journal. 2001, 13(3):127-137

[46] Usui M. Aeromechanics of low Reynolds number inflatable/rigidizable wings. Master thesis, Lexington: University of Kentucky, 2004

[47] Vidales H M G. Design, construction and test of the propulsion system of a solar UAV. Master thesis, Portugal: Technical University of Lisbon, 2013

[48] Wickenheiser A M, Garcia E. Conceptual design considerations for microwave-and solar-powered fuel-less aircraft. Journal of Aircraft. 2009, 46(2):510-519

[49] Yonemura S, Tsuruta H, Sudo S, Peng L C, Fook L S,Johar Z. Annual and El Niño-Southern Oscillation variations in observations of in situ stratospheric ozone over Peninsular Malaysia. Journal of Geophysical Research: Atmospheres, 2002, 107(D13):1-12

[50] Youli S,Nagasaka K. Monte Carlo simulation method used in reliability evaluation of a laboratory-based micro grid. In International MultiConference of Engineers and Computer Scientists, 2010, pp. 1-6

\section{How to cite this article:}

Idris A C, Dollah N, Saad M R, Sojipto S, Rahman M R A. New design algorithm and reliability testing of solar powered near-space flight vehicle for defense and security. $\mathrm{J}$. Fundam. Appl. Sci., 2017, 9(3S), 433-456. 